\title{
Imbalance between Th17 and regulatory T-cells in systemic lupus erythematosus
}

\author{
Weronika Kleczynska, Bogdan Jakiela, Hanna Plutecka, Mamert Milewski, \\ Marek Sanak, Jacek Musial
}

Department of Medicine, Jagiellonian University Medical College, Krakow, Poland

\begin{abstract}
Impaired function of regulatory T-cells (Treg) leads to a failure in immune tolerance and triggers autoimmunity. We analyzed whether the deficiency in Treg in systemic lupus erythematosus (SLE) is accompanied by an increase in effector T-cell responses. We studied the frequencies of IL-17A (Th17) and IFN $\gamma$ (Th1) producing $\mathrm{CD}^{+}$T-cells by flow cytometric detection of intracellular cytokines in PMA/ionomycin stimulated blood lymphocytes from seven patients with active SLE, eight with SLE in remission, and 11 healthy controls. Circulating Treg were evaluated as $\mathrm{CD} 4{ }^{+} \mathrm{CD} 25^{+}$lymphocytes expressing FoxP3. There was no difference in the percentage of Treg cells between the groups, but their absolute counts were decreased in active SLE (5 [1-7] cells $/ \mu \mathrm{L})$ compared to inactive SLE (11 [6-15]; $\mathrm{p}=0.05)$ and healthy controls $(16$ [10-20]; $\mathrm{p}<0.01)$. Both the frequency and numbers of Th1 cells were decreased in SLE compared to controls. No difference was observed in the number of Th17 cells, which resulted in a decreased Th1/Th17 ratio. In parallel, a higher Treg/Th17 ratio in healthy controls (2.2 [1.8-3.6]) compared to active SLE (1.1 [1.0-2.1]; $\mathrm{p}<0.05)$ was observed. There was a correlation between the number of Treg cells and disease activity status (SLEDAI, $r=-0.59$ ). SLE patients in the active phase of the disease are characterized by a deficiency in Treg cells and decreased Treg/Th17 ratio. This suggests that the imbalance between major T-cells subsets might be responsible for an increased proinflammatory response in the exacerbation of SLE. (Folia Histochemica et Cytobiologica 2011; Vol. 49, No. 4, pp. 646-653)
\end{abstract}

Key words: systemic lupus erythematosus, regulatory T-cells, Th17 cells, Th1 cells

\section{Introduction}

Systemic lupus erythematosus (SLE) is a systemic autoimmune disease characterized by an immune response against nuclear antigens, and deposition of immune complexes in target organs causing inflammation and tissue damage. Failure of T-cell tolerance towards self-antigens in genetically predisposed individuals and subsequent production of autoantibodies are the likely factors involved in pathogenesis of the disease. Controversy still exists regarding the con-

Correspondence address: J. Musial, Department of Medicine, Jagiellonian University Medical College, Skawinska Str. 8, 31-066 Krakow, Poland; tel.: (+ 48 12) 43052 66, fax: (+ 48 12) 43052 03; e-mail:mmmusia@cyf-kr.edu.pl tribution of specific T-helper cell subsets and related cytokines in the pathogenesis of SLE.

In addition to well characterized Th1 and Th 2 lymphocytes, naive $\mathrm{CD}^{+} \mathrm{T}$-cells can also differentiate towards Th17, a distinct subset of T-helper cells characterized by expression of the transcription factor ROR $\gamma \mathrm{t}$ [1]. Th17 cells secrete a profile of potent proinflammatory cytokines including IL-17A, IL-17F and IL-22, which act on a variety of cells in resident tissues and contribute to tissue injury [2]. Recent studies indicate that Th17 cells, rather than Th1 subset, are capable of inducing organ-specific autoimmunity in animal models $[3,4]$. Supporting this data, an increase in the fraction of Th17 cells and elevated levels of IL-23 (Th17 differentiation factor) and IL-17 type cytokines have been found in a number of autoimmune disorders [5-7]. 
The function of self-reacting effector T-cells is controlled by regulatory T-cells (Treg), yet another subpopulation of $\mathrm{CD}^{+}$lymphocytes which express transcription factor FoxP3 and participate in maintaining peripheral tolerance [8]. Though the concept of the preventive role of Treg cells in autoimmunity is widely accepted, data regarding SLE is inconsistent [9]. The studies on circulating Treg cells characterized phenotypically indicate either a decrease [10-12], an increase [13] or no change in their number $[14,15]$ compared to healthy controls. A decrease in Treg numbers or their functional deficiency seem to be associated with the active stage of the disease [16]. Two recent studies have also shown the Treg to Th17 ratio to be decreased in exacerbated SLE $[12,14]$.

Considering that lymphopenia is a common clinical finding in lupus patients, it would be interesting to discover whether a decrease in Treg observed in active disease is indeed paralleled by an increase in the number of effector Th1 and Th17 cells.

In this study, we aimed therefore to analyze the balance between effector and regulatory T-cell subsets in SLE, by studying both the frequencies and absolute counts of circulating Th1, Th17 and FoxP3 ${ }^{+}$ expressing Treg cells.

\section{Material and methods}

Patients and study design. Fifteen patients with SLE (eight patients in the active phase of the disease and seven in remission) diagnosed according to the American College of Rheumatology criteria were studied. Activity of the disease was evaluated using the SLE Disease Activity Index score (SLEDAI) [17]. Disease exacerbation was defined as a SLEDAI score $\geq 5$. At the time of enrolment, SLE patients were not being treated with immunosuppressive drugs, except for glucocorticoids. Clinical and laboratory characteristics of the SLE patients studied are summarized in Table 1. Eleven healthy volunteers served as controls. The study was approved by the Ethics Committee of the Jagiellonian University and informed consent was obtained from all participants.

Isolation of peripheral blood lymphocytes. Peripheral blood mononuclear cells (PBMC) were isolated from heparinized peripheral venous blood by Histopaque 1.077 (Sigma-Aldrich, St. Louis, MO, USA) gradient centrifugation. PBMC were resuspended in RPMI-1640 (Sigma-Aldrich) with 10\% human $\mathrm{AB}$ serum (ABS, Linz, Austria) and incubated for 30 $\min$ at $37^{\circ} \mathrm{C}$ in a plastic flask to deplete monocytes. Non-adherent PBL (peripheral blood lymphocytes) were cryopreserved for further experiments completed within one month.

Lymphocyte immunophenotyping. To identify major subpopulations of T-cells, PBL were triple stained with labeled monoclonal antibodies (CD45, CD3, CD4, CD8; all from BD Biosciences) for 30 minutes, washed in phosphate buffered saline (PBS), and analyzed by flow cytometry (Coulter EPICS XL, Beckman Coulter, Fullerton, CA, USA). To identify regulatory T-cells, PBL were labeled with PerCP-CD4 and PE-CD25, and then fixed (FACS Lysing Solution, BD Biosciences), permeabilized (0.2\% saponin, Sigma-Aldrich), and intracellularly stained with FITC-antiFoxP3 (eBiosciences, San Diego, CA, USA). Treg cells were recognized as $\mathrm{CD}^{+}$cells expressing $\mathrm{CD} 25^{\text {high }}$ and FoxP3 ${ }^{+}$ protein (Figures 1A, B).

\section{Stimulation of peripheral blood lymphocytes and detection of} cytokines. Cryopreserved PBL were thawed, washed in RPMI$-1640(10 \%$ ABS $)$ and pre-cultured for 2 hours $\left(2 \times 10^{6}\right.$ cells per well) before stimulation. PBL were then left untreated (baseline control) or incubated for 5 hours with PMA (final 50 $\mathrm{ng} / \mathrm{mL}$; Sigma-Aldrich) and ionomycin $(0.7 \mu \mathrm{g} / \mathrm{mL}$; Sigma-Aldrich) in the presence of brefeldin-A $(10 \mu \mathrm{g} / \mathrm{mL}$; Sigma-Aldrich). Cells were labeled with PerCP-CD4 (BD Biosciences) for 15 minutes, fixed and permeabilized with Cytofix/Cytoperm (BD Biosciences) and stained intracellularly with monoclonal antibodies: FITC-IFN $\gamma$ (BD Biosciences) and PE-IL-17A (eBiosciences). Samples were washed in Perm/Wash buffer and analyzed by flow cytometry. Specificity of cytokine staining was confirmed with appropriate isotype controls. Cytokine expressing $\mathrm{CD}^{+}{ }^{+}$cells were classified as Th1 (producing only IFN $\gamma$ ), Th17 (producing IL-17A, but not IFN $\gamma$ ) or Th1/17 (producing both IL-17A and IFN $\gamma$ ). Representative flow cytometry dot plots are shown in Figures 1C, D.

Statistical analysis. Statistical analysis was performed using GraphPad Prism 4.0 (GraphPad Software, Inc., San Diego, CA, USA). All data was presented as medians and IQR (interquartile range). Differences between two groups were determined by a Mann-Whitney U or Friedman test. Differences between the three groups were analyzed with ANOVA or Kruskal-Wallis test. Spearman's rank sum test was used to analyze correlation coefficients; a p-value $<0.05$ was considered significant.

\section{Results}

\section{Decrease in absolute count of regulatory T-cells in active SLE}

Total lymphocyte and T-cell (both $\mathrm{CD} 4^{+}$and $\mathrm{CD} 8^{+}$) count was decreased in SLE patients in comparison with healthy subjects (Table 2). Interestingly, the percentage of individual T-cell populations did not differ between the groups (data not shown). As expected, the decrease in lymphocyte count was restricted to SLE patients only during the disease exacerbation (Figures 2A-C). We found a significantly lower num- 


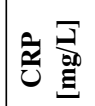

已镸

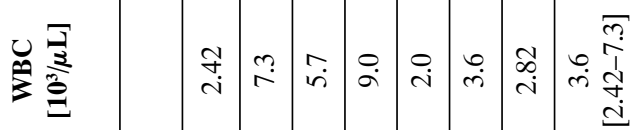

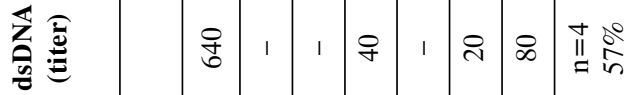

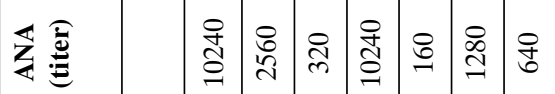

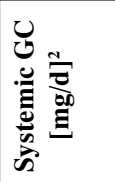

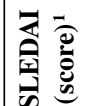

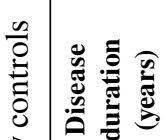

空

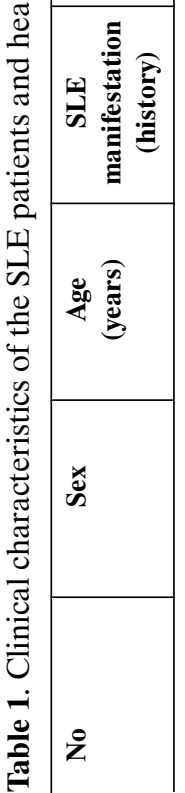

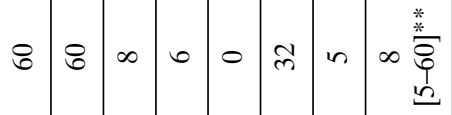

$\because$ ㄷำ

$\because \ln =m \quad 0 \approx \approx 0 \frac{\bar{I}}{I}$

舀悹

:

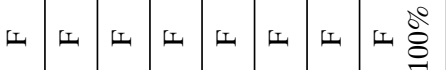

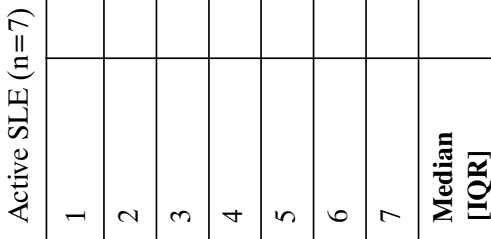

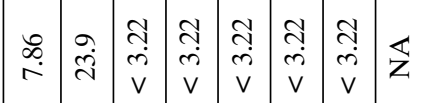

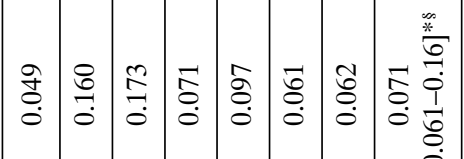

$\stackrel{\leftrightarrow}{\circ}$

\section{(1)}

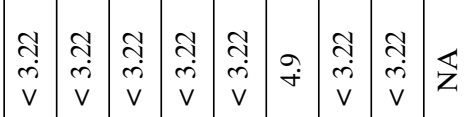

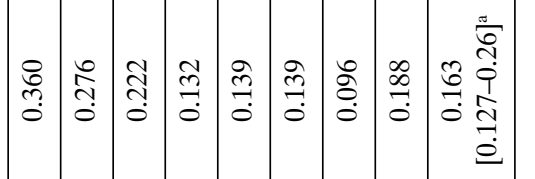

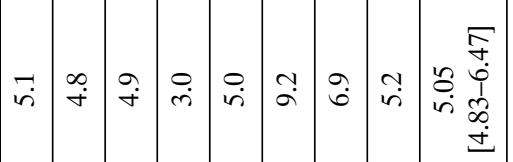

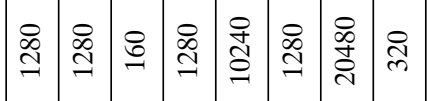

- 0.00000 t

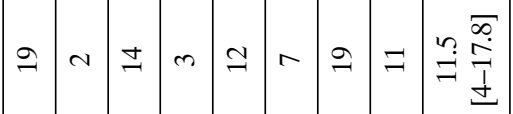

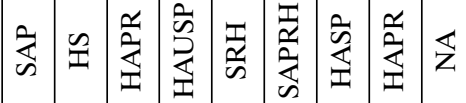

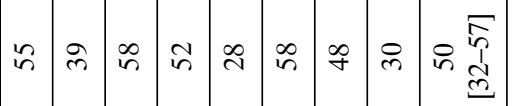

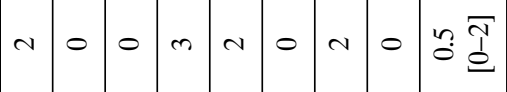

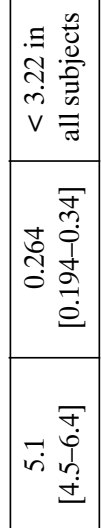

$\frac{\ddot{s}}{\frac{\tilde{0}}{0}}$

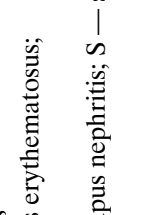

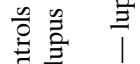

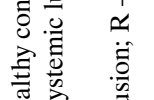

政

을

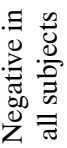

8

11 ठ

苛文

$\begin{array}{cc}v & 0 \\ 0.00 & 0\end{array}$

所完。

$\overleftrightarrow{z}$

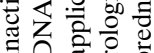

은

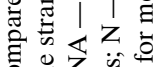

$\varangle$

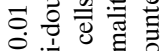

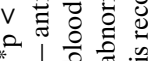

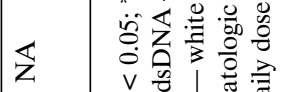

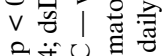

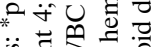

is

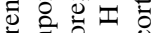

$\overleftrightarrow{z}$ 过

है

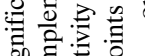

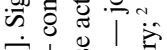
宁।

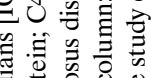

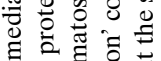

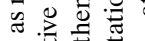
证

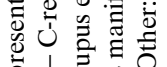

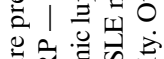

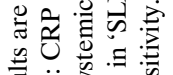

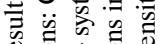

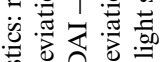

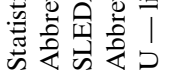


Table 2. Peripheral blood lymphocyte subpopulations in SLE patients and controls

\begin{tabular}{|c|c|c|c|}
\hline & Unit & Healthy subjects $(n=11)$ & SLE $(n=15)$ \\
\hline Lymphocytes & Cells $/ \mu \mathrm{L}$ & 1939 [1591-2059] & $1158[1073-1877]^{*}$ \\
\hline $\mathrm{CD}^{+}$ & Cells $/ \mu \mathrm{L}$ & 1376 [1194-1486] & $907[653-1253]^{*}$ \\
\hline $\mathrm{CD}^{+}{ }^{+}$ & Cells $/ \mu \mathrm{L}$ & $673[556-928]$ & $394[298-664]^{\S}$ \\
\hline $\mathrm{CD}^{+}$ & Cells $/ \mu \mathrm{L}$ & 540 [406-615] & $326[270-492]^{\S}$ \\
\hline $\mathrm{CD} 4 / \mathrm{CD} 8$ & Ratio & $1.15[1.09-2.15]$ & $1.20[0.96-1.45]$ \\
\hline \multicolumn{4}{|c|}{ Subpopulations of $\mathrm{CD} 4^{+}$lymphocytes $\left(\%\right.$ of $\left.\mathrm{CD}^{+}\right)$} \\
\hline Treg & $\%$ of $\mathrm{CD}^{+}+$ & $2.1[1.9-2.8]$ & $1.8[0.9-3.0]$ \\
\hline Th1 & $\%$ of $\mathrm{CD}^{+}$ & $25.2[20.4-35.6]$ & $16.2[14.6-25.5]^{\S \S}$ \\
\hline Th17 & $\%$ of $\mathrm{CD}^{+}+$ & $0.92[0.77-1.15]$ & $1.07[0.65-1.52]$ \\
\hline Th1/17 & $\%$ of $\mathrm{CD}^{+}$ & $0.17[0.12-0.22]$ & $0.14[0.06-0.21]$ \\
\hline \multicolumn{4}{|c|}{ Subpopulations of CD4+ lymphocytes (absolute counts) } \\
\hline Treg & Cells $/ \mu \mathrm{L}$ & $15.7[10.2-19.7]$ & $7.1[4.8-12.9]^{* *}$ \\
\hline Th1 & Cells $/ \mu \mathrm{L}$ & 198 [169-211] & $100[34-139]^{* *}$ \\
\hline Th17 & Cells $/ \mu \mathrm{L}$ & $6.0[4.5-9.2]$ & $4.8[3.7-7.5]$ \\
\hline Th1/17 & Cells $/ \mu \mathrm{L}$ & $1.1[0.78-1.34]$ & $0.7[0.41-0.95]^{\S}$ \\
\hline \multicolumn{4}{|c|}{ Ratio of particular $\mathrm{CD} 4^{+}$subpopulations } \\
\hline Th1/Th17 & Ratio & $29.5[17.6-38.7]$ & $21.6[13.9-25.0]^{*}$ \\
\hline Th1/Treg & Ratio & $11.3[8.7-21.7]$ & $13.0[5.4-19.8]$ \\
\hline Treg/Th17 & Ratio & $2.18[1.79-3.6]$ & $1.16[1.06-2.09]^{* *}$ \\
\hline
\end{tabular}

Abbreviations: SLE — systemic lupus erythematosus; Treg — regulatory T-cells; Th1 - CD4 ${ }^{+}$cells producing only IFN $\gamma$;

Th17 - CD4 $4^{+}$cells producing only IL-17; Th1/17 - CD4 ${ }^{+}$cells producing both IFN $\gamma$ and IL-17

Statistics: Results are presented as medians [IQR]. p-values: ${ }^{* *} \mathrm{p}<0.01 ;{ }^{*} \mathrm{p}<0.05 ;{ }^{8} \mathrm{p}=0.05,{ }^{8 s} \mathrm{p}=0.1$ compared to healthy controls

ber of $\mathrm{CD} 25^{\text {high }} \mathrm{FoxP}^{+}$regulatory T-cells in active SLE compared to the disease remission $(\mathrm{p}=0.05)$ and to healthy subjects $(\mathrm{p}<0.01)$ (Figure $2 \mathrm{D})$. Interestingly, no difference was observed in the percentage (within $\mathrm{CD}_{4}{ }^{+}$fraction) of Treg cells (Table 2). Nevertheless, individuals characterized by a very low percentage of Treg cells $\left(<1.5 \%\right.$ of $\left.\mathrm{CD}^{+}\right)$were found only in the SLE group.

\section{Deficiency in IFNy producing $\mathrm{CD4}^{+}$T-cells and decrease in Th1/T17 ratio in SLE}

The percentages of individual subpopulations of $\mathrm{CD} 4{ }^{+}$cells were similar between the groups, with only a trend $(p=0.1)$ towards a higher percentage of Th1 cells in the control group (Table 2). When analyzing the absolute counts of a lineage committed $\mathrm{CD}^{+}$ cells, we found a significant $(p<0.05)$ decrease in the number of Th1 cells both for active and inactive SLE (Figure 2E). There was no difference in the number of Th17 cells (Figure 2F). In consequence, Th1/ /Th17 ratio was decreased both in active (22.2 [8.8-27.7]) and inactive SLE (19.2 [15.4-23.3]) compared to controls (29.5 [17.6-38.7]; $\mathrm{p}<0.05)$.

\section{Decreased Treg/Th17 ratio in active SLE}

Next we compared the ratios between effector and regulatory subpopulations of $\mathrm{CD}^{+}{ }^{+}$cells. We noticed a considerably higher ratio of Treg to Th17 cells in healthy controls (2.2 [1.8-3.6]) compared to active (1.1 [1.0-2.1]; $p<0.05)$ but not inactive SLE (1.5 [1.1$-2.9] ; p=N S)$. Treg/Th17 ratio did not correlate with clinical (SLEDAI) or laboratory markers (complement component $\mathrm{C} 4$ ) of disease activity. In contrast, the ratio of Th1 to Treg cells did not differ between the groups (see Table 2).

\section{The number of Treg cells correlate with markers of disease activity}

There was a significant inverse correlation between SLEDAI score and the serum level of complement component C4 (Figure 3A) and lymphocyte count (Figure 3B). We also found a strong positive correlation between the number of Treg cells and the concentration of C4 (Figure 3C). Likewise, a significant negative correlation of Treg count with SLEDAI score was observed $(r=-0.59 ; p=0.01)$. In contrast, the 
A

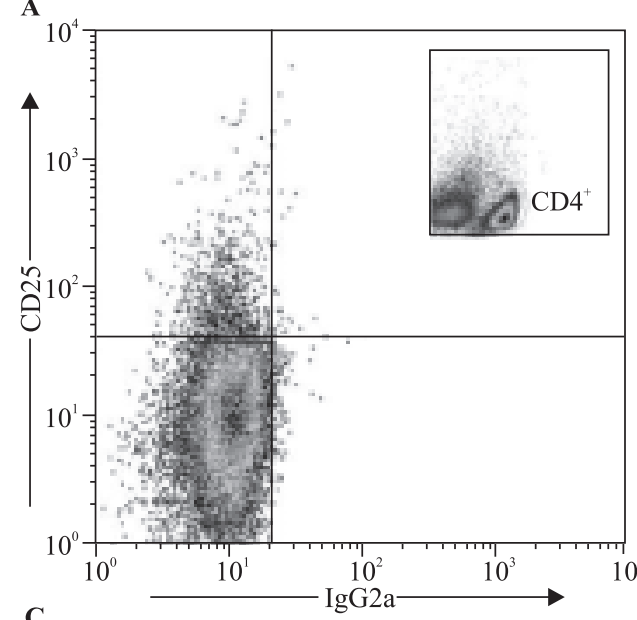

C

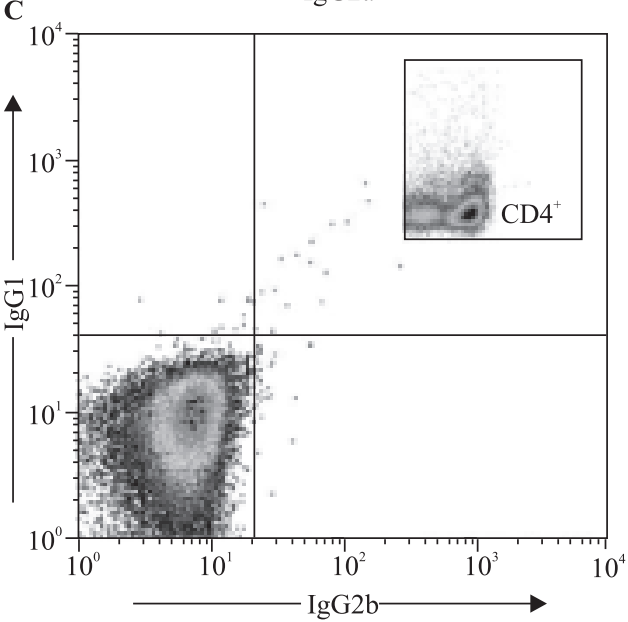

B

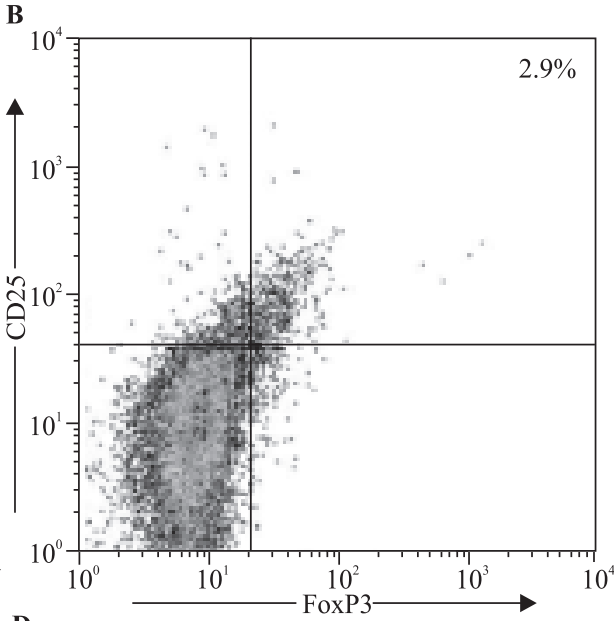

D

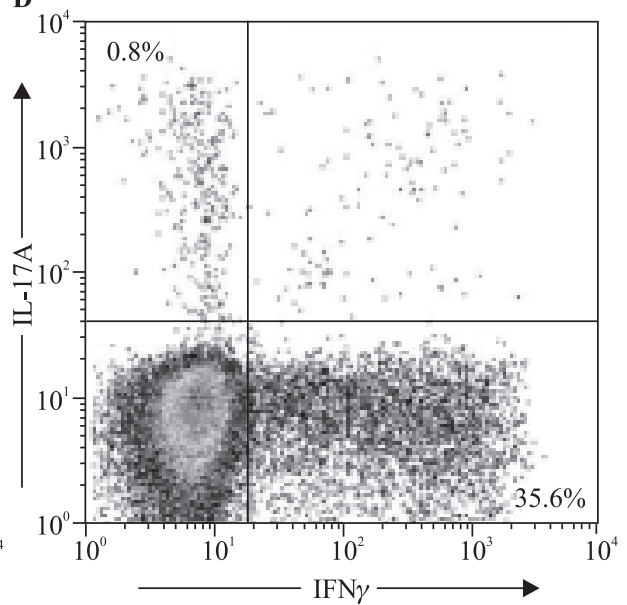

Figure 1. Flow cytometry dot-plots showing the gating strategy used in identification of regulatory T-cells and cytokineproducing $\mathrm{CD}^{+}{ }^{+}$cells (representative data of a healthy subject). A. IgG2a Isotype control and CD25 staining of CD4 ${ }^{+}$ lymphocytes (gate in inset) in order to identify $\mathrm{CD} 4{ }^{+} \mathrm{CD} 25^{\text {high }}$ cells within PBL fraction. B. Staining for CD25 and FoxP3 to distinguish $\mathrm{CD} 25^{\text {high }} \mathrm{FoxP}^{+}$regulatory T-cells. C. Isotype control staining of PMA/ionomycin stimulated PBL (gating on $\mathrm{CD}^{+}$cells is shown in inset). D. Staining for IL-17A and IFN $\gamma$ to detect Th1 (expression of IFN $\gamma$ only), Th17 (only IL17A) and Th1/17 cells (expression of both cytokines)

number of Th17 and Th1 cells did not correlate with SLEDAI or the serum level of C4.

\section{Discussion}

The human immune system is equipped with a number of mechanisms involved in maintaining immune tolerance and protection against autoimmunity. Treg lymphocytes are the key cells controlling the autoimmunization process. Their role is illustrated by an active and dominant control over the function of effector T cells. Of these, IL-17A secreting $\mathrm{CD}^{+}$cells have recently been identified as a major subpopulation involved in autoimmune disorders [5].

In patients with active SLE, both the increase in percentage of circulating Th17 cells, $[12,18,19]$ and elevated serum concentration of IL-17A have been described [20-24]. However, in some reports, no association of IL-17 with clinical markers of disease activity was found $[22,23]$. These inconsistencies are partly due to enrolment of patients regardless of the immunosuppressive therapy or at a different phase of their disease. Indeed, the numbers of Th17 cells in peripheral blood are usually higher in patients with renal disease [12].

In the present study, we did not observe any differences in the frequency of Th17 cells between SLE patients and healthy controls. Nevertheless, the percentage of Th1 cells, and absolute counts of both Th1 and Treg cells were significantly decreased in the SLE exacerbation. In consequence, the Th1/Th17 and Treg/ /Th1 ratios were lower in SLE compared to healthy subjects. We also observed a clear correlation between the number of Treg cells and markers of disease activity (e.g. SLEDAI score and serum C4 concentration), suggesting their potential role in disease exacerbation. The decrease in absolute count of Treg cells in SLE was also observed by Henriques et al. [25]. 

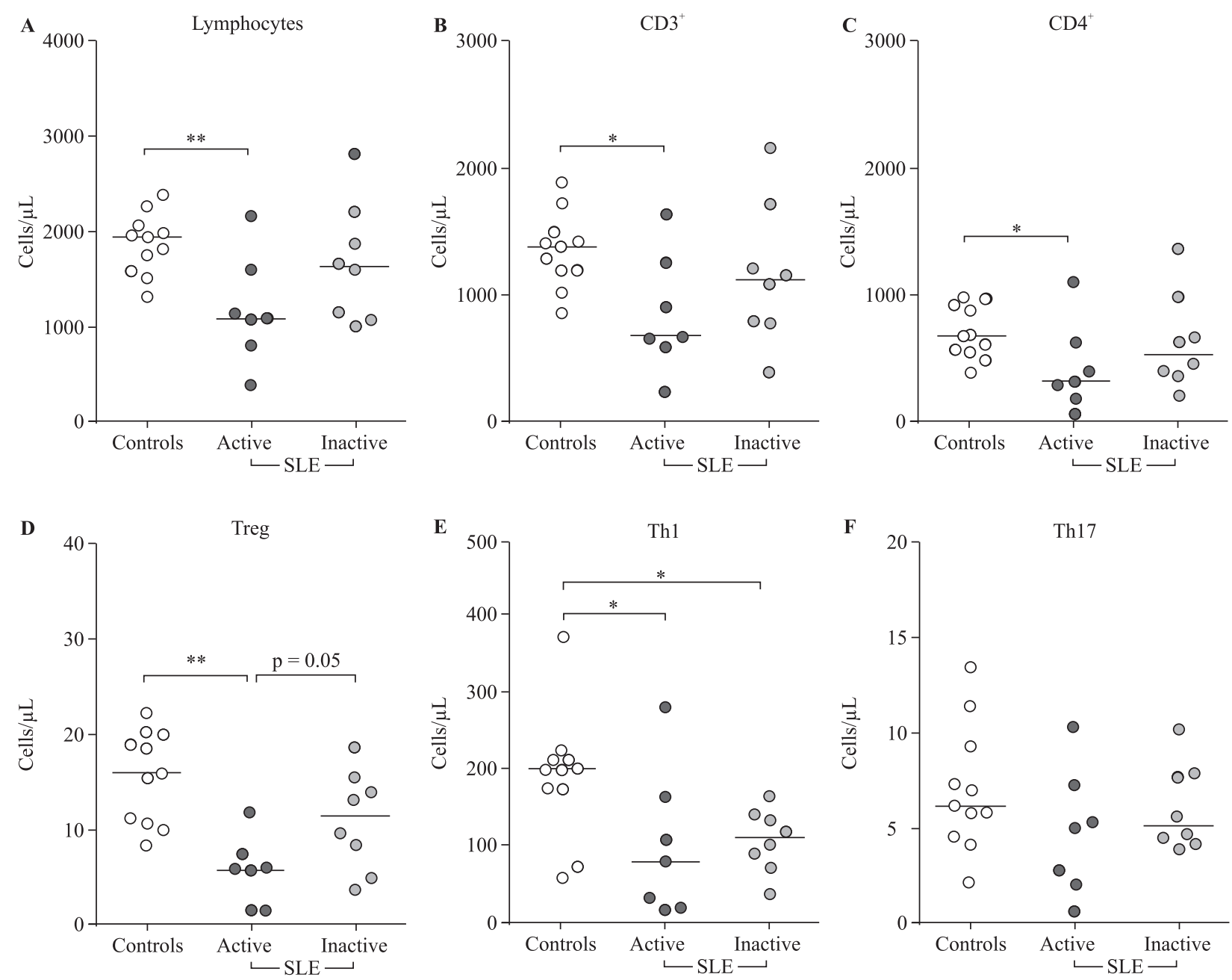

Figure 2. Absolute counts of lymphocyte subpopulations in SLE patients (stratified by the activity of the disease) and the control group: total lymphocytes (A), CD3 ${ }^{+}$T-cells (B), CD3/CD4+ T-helper cells $(\mathbf{C})$, regulatory T-cells $(\mathbf{D})$, Th1 cells $(\mathbf{E})$ and Th17 cells $(\mathbf{F})$. Horizontal bars on graphs indicate medians, ${ }^{*} \mathrm{p}<0.05,{ }^{* *} \mathrm{p}<0.01$

A

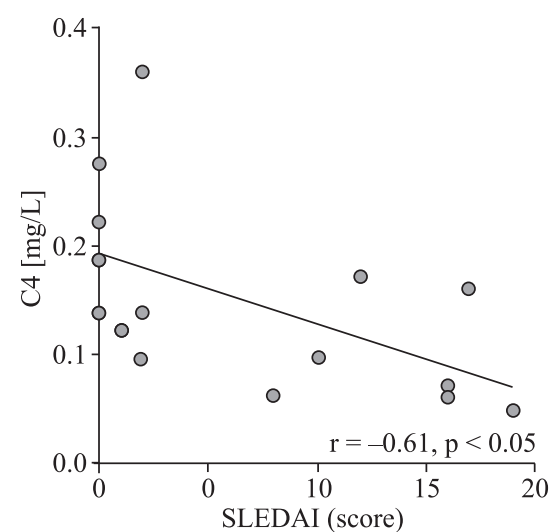

B

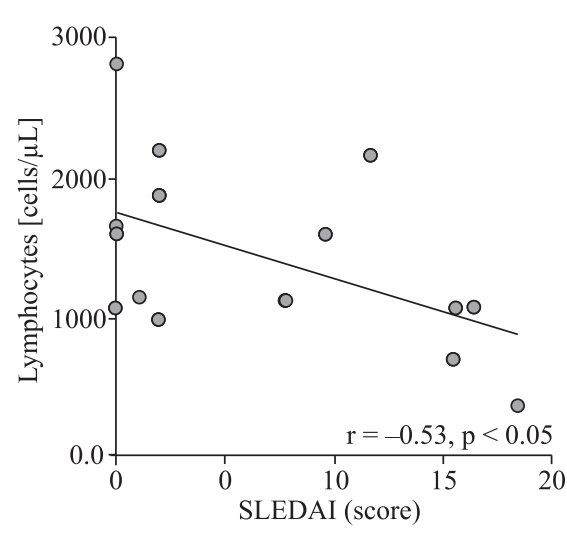

C

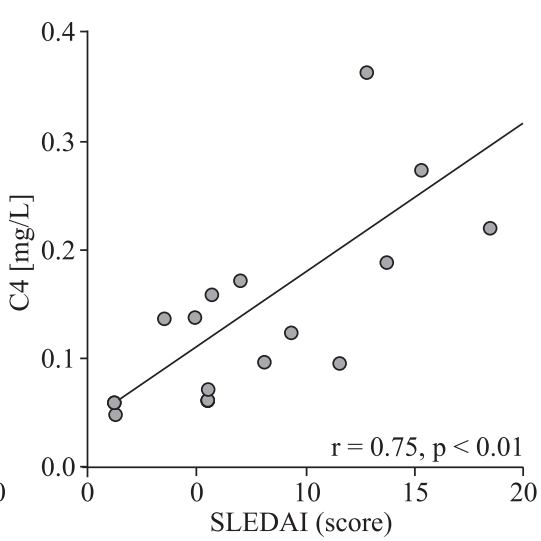

Figure 3. Associations of selected clinical and laboratory parameters in SLE patients $(n=15)$. A. Correlation of complement component $\mathrm{C} 4$ concentration and SLEDAI score. B. Correlation of SLEDAI score and total lymphocyte count. C. Correlation of $\mathrm{C} 4$ and Treg count 
Additionally, a decrease in the number of circulating Treg cells is a characteristic feature of active SLE patients with lymphopenia [26]. Our results suggest that lymphopenia associated with exacerbation of SLE may affect primarily Treg and Th1 fractions, but not Th17, resulting in further dysregulation between the main effector and regulatory T-cell subsets.

The decrease in Th1 to Th17 ratio in SLE has been observed by Shah et al. [19], who found an increased frequency of IL-17A producing $\mathrm{CD}^{+}{ }^{+} \mathrm{T}$-cells in peripheral blood but no change in Th1 fraction. Also recently, a considerable increase in Th17 to Treg ratio, which correlated with SLEDAI score, was observed by Xing et al. [12]. Another research group described an elevated ratio of Th17 to regulatory T-cells in patients with active SLE, with no evidence of an increase in the percentage of Th17, pointing to the imbalance between these subsets as the cause of disease exacerbation [14]. So it is likely that the dysregulation between effector and regulatory T-cells occurring in lupus could be attributed to immune resistance of self-reacting effector cells to regulatory lymphocytes, or defective suppressory activity of the latter. Such mechanisms were initially suggested in a MRL/lpr mice model of lupus [27] and further confirmed in ex vivo studies on human cells $[10,11]$.

The possible imbalance between Th17 and Treg cells is supported by molecular studies showing the presence of reciprocal interaction between these subpopulations. Though both Th17 and inducible Treg cells require the same cytokine, TGF- $\beta 1$, during the early stage of differentiation, in the presence of pro-inflammatory cytokines IL- $1 \beta$ and IL-6, FoxP3 is down-regulated and T-cells with transitional phenotype express a set of proteins essential for Th17 development (e.g. ROR $\gamma$ t and IL-23R) [28]. Additionally, IL-2, which is required for the expansion and maintenance of FoxP3 expressing Treg cells, has been found to inhibit the development of Th17 cells [29]. Therefore, the counteractive effects of IL- 2 and IL- 6 on the differentiation of Th17 and Treg in the periphery may hamper immunoregulatory responses and facilitate the persistence of autoimmune inflammation.

In summary, our data indicates that patients with active SLE are characterized by a relative deficiency in Th1 and Treg cells compared to the Th17 subset. The imbalance between major effector and suppressory subpopulations of $\mathrm{CD}^{+}$cells could result in increased proinflammatory response mediated by Th17 cells, and may, at least partially, explain the mechanism operational at disease exacerbation. Additionally, decreased numbers of Treg in the peripheral blood of lupus patients correlated with clinical and laboratory markers of disease flare. These results confirm earlier reports on the potential use of functional T-cell phenotyping in the assessment of SLE activity.

Further studies are needed, however, to explain how Th17/Treg equilibrium translates into a specific array of lupus symptoms, and whether biological agents aiming at mediators of Th17 axis may be of value in SLE therapy.

\section{Conflict of interests}

No conflict of interest has been declared by the authors.

\section{References}

1. Hemdan NY, Birkenmeier G, Wichmann G et al. Interleukin-17-producing T helper cells in autoimmunity. Autoimmun Rev. 2010;9:785-792.

2. Miossec P, Korn T, Kuchroo VK. Interleukin-17 and type 17 helper T cells. $N$ Engl J Med. 2009;36:888-898.

3. Murphy CA, Langrish CL, Chen Y et al. Divergent proand antiinflammatory roles for IL-23 and IL-12 in joint autoimmune inflammation. J Exp Med. 2003;198:1951$-1957$.

4. Zhang GX, Gran B, Yu S et al. Induction of experimental autoimmune encephalomyelitis in IL-12 receptor-beta 2-deficient mice: IL-12 responsiveness is not required in the pathogenesis of inflammatory demyelination in the central nervous system. J Immunol. 2003;170:2153-2160.

5. Leung S, Liu X, Fang L, Chen X, Guo T, Zhang J. The cytokine milieu in the interplay of pathogenic Th1/Th17 cells and regulatory T cells in autoimmune disease. Cell Mol Immunol. 2010;7:182-189.

6. Jager A, Kuchroo VK. Effector and regulatory T-cell subsets in autoimmunity and tissue inflammation. Scand J Immunol. 2010;72:173-184.

7. Gaffen SL. The role of interleukin-17 in the pathogenesis of rheumatoid arthritis. Curr Rheumatol Rep. 2009;11:365-370.

8. Buckner JH. Mechanisms of impaired regulation by CD4(+)CD25(+)FOXP3(+) regulatory $\mathrm{T}$ cells in human autoimmune diseases. Nat Rev Immunol. 2010;10:849-859.

9. Kuhn A, Beissert S, Krammer PH. CD4(+)CD25 (+) regulatory $\mathrm{T}$ cells in human lupus erythematosus. Arch Dermatol Res. 2009;301:71-81

10. Valencia X, Yarboro C, Illei G, Lipsky PE. Deficient $\mathrm{CD} 4{ }^{+} \mathrm{CD} 25^{\text {high }} \mathrm{T}$ regulatory cell function in patients with active systemic lupus erythematosus. J Immunol. 2007; 178:2579-2588.

11. Lee HY, Hong YK, Yun HJ, Kim YM, Kim JR, Yoo WH. Altered frequency and migration capacity of $\mathrm{CD} 4{ }^{+} \mathrm{CD} 25^{+}$ regulatory $\mathrm{T}$ cells in systemic lupus erythematosus. Rheumatology (Oxford). 2008;47:789-794.

12. Xing Q, Wang B, Su H, Cui J, Li J. Elevated Th17 cells are accompanied by FoxP3 ${ }^{+}$Treg cells decrease in patients with lupus nephritis. Rheumatol Int. Accepted 18 Jan 2011; doi: 10.1007/s00296-010-1771-0.

13. Yan B, Ye S, Chen G, Kuang M, Shen N, Chen S. Dysfunctional $\mathrm{CD}^{+}{ }^{+}, \mathrm{CD} 25^{+}$regulatory $\mathrm{T}$ cells in untreated active systemic lupus erythematosus secondary to interferon-alphaproducing antigen-presenting cells. Arthritis Rheum. 2008;58:801-812. 
14. Ma J, Yu J, Tao X, Cai L, Wang J, Zheng SG. The imbalance between regulatory and IL-17-secreting $\mathrm{CD}^{+} \mathrm{T}$ cells in lupus patients. Clin Rheumatol. 2010;29:1251-1258.

15. Alvarado-Sanchez B, Hernandez-Castro B, Portales-Perez D et al. Regulatory $\mathrm{T}$ cells in patients with systemic lupus erythematosus. J Autoimmun. 2006;27:110-118.

16. Gerli R, Nocentini G, Alunno A et al. Identification of regulatory $\mathrm{T}$ cells in systemic lupus erythematosus. Autoimmun Rev. 2009;8:426-430.

17. Bombardier C, Gladman DD, Urowitz MB, Caron D, Chang $\mathrm{CH}$. Derivation of the SLEDAI. A disease activity index for lupus patients. The Committee on Prognosis Studies in SLE. Arthritis Rheum.1992;35:630-640.

18. Yang J, Chu Y, Yang X et al. Th17 and natural Treg cell population dynamics in systemic lupus erythematosus. $A r$ thritis Rheum. 2009;60:1472-1483.

19. Shah K, Lee WW, Lee SH et al. Dysregulated balance of Th17 and Th1 cells in systemic lupus erythematosus. Arthritis Res Ther. 2010;12:R53.

20. Wong CK, Ho CY, Li EK, Lam CW. Elevation of proinflammatory cytokine (IL-18, IL-17, IL-12) and Th2 cytokine (IL-4) concentrations in patients with systemic lupus erythematosus. Lupus. 2000;9:589-593.

21. Wong CK, Lit LC, Tam LS, Li EK, Wong PT, Lam CW. Hyperproduction of IL-23 and IL-17 in patients with systemic lupus erythematosus: implications for Th17-mediated inflammation in auto-immunity. Clin Immunol. 2008;127:385-393.

22. Cheng F, Guo Z, Xu H, Yan D, Li Q. Decreased plasma IL22 levels, but not increased IL17 and IL23 levels, corre- late with disease activity in patients with systemic lupus erythematosus. Ann Rheum Dis. 2009;68:604-606.

23. Zhao XF, Pan HF, Yuan $\mathrm{H}$ et al. Increased serum interleukin 17 in patients with systemic lupus erythematosus. $\mathrm{Mol}$ Biol Rep. 2010;37:81-85.

24. Chen XQ, Yu YC, Deng HH et al. Plasma IL-17A is increased in new-onset SLE patients and associated with disease activity. J Clin Immunol. 2010;30:221-225.

25. Henriques $\mathrm{A}$, Ines $\mathrm{L}$, Couto $\mathrm{M}$ et al. Frequency and functional activity of Th17, Tc17 and other T-cell subsets in Systemic Lupus Erythematosus. Cell Immunol. 2010;264: 97-103.

26. Gomez-Martin D, Diaz-Zamudio M, Vanoye G, Crispin JC, Alcocer-Varela J. Quantitative and functional profiles of $\mathrm{CD}^{+}$lymphocyte subsets in systemic lupus erythematosus patients with lymphopenia. Clin Exp Immunol. 2011;164: $17-25$.

27. Monk CR, Spachidou M, Rovis F et al. MRL/Mp $\mathrm{CD}^{+}, \mathrm{CD} 25^{-} \mathrm{T}$ cells show reduced sensitivity to suppression by $\mathrm{CD} 4^{+}, \mathrm{CD} 25^{+}$regulatory $\mathrm{T}$ cells in vitro: a novel defect of $\mathrm{T}$ cell regulation in systemic lupus erythematosus. Arthritis Rheum. 2005;52:1180-1184.

28. Zhou L, Lopes JE, Chong MM et al. TGF-beta-induced Foxp3 inhibits $\mathrm{T}(\mathrm{H}) 17$ cell differentiation by antagonizing RORgammat function. Nature. 2008;453:236-240.

29. Zheng SG, Wang J, Horwitz DA. Cutting edge: Foxp $3{ }^{+} \mathrm{CD} 4{ }^{+} \mathrm{CD} 25^{+}$regulatory $\mathrm{T}$ cells induced by IL-2 and TGF-beta are resistant to Th17 conversion by IL-6. J Immunol. 2008;180:7112-7116.

Submitted: 20 April, 2011 Accepted after reviews: 18 September, 2011 